\title{
HUBUNGAN ANTARA KEPEMIMPINAN VISIONER KEPALA SEKOLAH DAN KEINOVATIFAN DENGAN EFEKTIVITAS KERJA GURU
}

\author{
Siti Halimah $\mathbf{S}^{\mathbf{1}}$, Rita Retnowati ${ }^{2}$, Herfina ${ }^{2}$ \\ ${ }^{1}$ Kepala Sekolah MI Swasta Kecamatan Cidahu Kabupaten Sukabumi \\ ${ }^{2}$ Program Pascasarjana Universitas Pakuan Bogor \\ Email:pasca@unpak.ac.id
}

\begin{abstract}
This study was conducted to see the relationship between the Principal Visionary Leadership and Innovation as well as the Teacher's Work Effectiveness.The research was carried out in 15 private Islamic schools in Cicurug Subdistrict, Sukabumi District, West Java Province in 2018 with a sample of 105 of the population which 142 taken by proportional random sampling. The method used is survey, and the data analysis techniques to using correlation statistical tests and simple linear regression and multiple regression and linear. The findings of research are: (1) There was a significant positive relationship between Principal Visionary Leadership $\left(X_{1}\right)$ and Teacher's Work Effectiveness $(Y)$ with correlation coefficient ry $y_{1}=0$, 5486; (2) There is a significant positive relationship between Innovation variable $\left(X_{2}\right)$ and Teacher Work Effectiveness (Y) with ry2 correlation coefficient of 0.8028 ; (3) There is a significant positive relationship between the Principal Visionary Leadership $\left(X_{1}\right)$ and Innovation $\left(X_{2}\right)$ variables together with the Teacher's Work Effectiveness $(Y)$ with Ry 12 correlation coefficient is 0.8144. Based on these findings, it can be concluded that the Teacher's Work Effectiveness can be improved through the Visionary Leadership of School Principals and Innovation.
\end{abstract}

Keywords: Principal Visionary Leadership, Innovation, Teacher Work Effectiveness.

\begin{abstract}
ABSTRAK
Penelitian ini dilakukan untuk mempelajari hubungan antara Kepemimpinan Visioner Kepala Sekolah dan Inovasi Guru dengan Efektivitas Kerja Guru. Penelitian dilaksanakan di 15 Madrasah Ibtidaiyah Swasta di Wilayah Kecamatan Cicurug Kabupaten Sukabumi Propinsi Jawa Barat pada tahun 2018 dengan sampel 105 dari populasi 142 yang diambil secara Proporsional Random Sampling. Metode yang digunakan yaitu survai dan teknik analisis data menggunakan uji statistik korelasi dan regresi linier sederhana serta regresi dan linier ganda. Hasil penelitian menghasilkan tiga kesimpulan yaitu, pertama, terdapat hubungan positif yang signifikan antara Kepemimpinan Visioner Kepala Sekolah $\left(\mathrm{X}_{1}\right)$ dan Efektivitas Kerja Guru (Y) dengan koefisien korelasi $\mathrm{r}_{\mathrm{y} 1}=0,5486$. Kedua, Terdapat hubungan positif yang signifikan antara variabel Inovasi $\left(\mathrm{X}_{2}\right)$ dengan Efektivitas Kerja Guru $(\mathrm{Y})$ dengan koefisien korelasi $\mathrm{r}_{\mathrm{y} 2}$ sebesar 0,8028 Ketiga terdapat hubungan positif signifikan antara variabel Kepemimpinan Visioner Kepala Sekolah $\left(\mathrm{X}_{1}\right)$ dan Inovasi $\left(\mathrm{X}_{2}\right)$ secara bersama-sama dengan Efektivitas Kerja Guru (Y) dengan koefisien korelasi $\mathrm{R}_{\mathrm{y} 12}$ sebesar 0,8144. Berdasarkan hal-hal tersebut dapat disimpulkan bahwa Efektivitas Kerja Guru dapat ditingkatkan melalui Kepemimpinan Visioner Kepala Sekolah dan Inovasi.
\end{abstract}

Kata Kunci : Kepemimpinan Visioner Kepala Sekolah, Inovasi, Efektivitas Kerja Guru. 


\section{PENDAHULUAN}

Kemajuan ilmu pengetahuan dan teknologi semakin hari semakin pesat perkembangannya, sehingga menuntut perubahan mendasar dalam berbagai bidang kehidupan, ekonomi, politik, tatanan sosial budaya, termasuk pendidikan. Pemerintah melakukan berbagai upaya untuk meningkatkan kualitas pendidikan dalam rangka menselaraskan dengan kemajuan jaman. Tetapi pada kenyataannya upaya tersebut banyak menemukan kegagalan, sehingga tujuan pendidikan nasional untuk mencerdaskan kehidupan bangsa melalui peningkatan mutu pada setiap jenis dan jenjang pendidikan belum dapat terwujudkan.

Kualitas suatu bangsa tidak terlepas dari kualitas pendidkan. Pendidikan harus mampu menyediakan lingkungan yang berfungsi untuk mengembangkan bakat dan kemampuan peserta didik secara optimal. Pendidikan menentukan perkembangan dan perwujudan individu. Kemudian individu salah satunya terbentuk sebagai hasil dari pendidikan yang baik. Masalah manajemen yang kurang tepat, kemudian penempatan tenaga pendidik yang tidak sesuai bidang dan keahliannya hal ini pun merupakan bagian dari permasalahan dibidang pendidikan. Mempersiapkan Sumber Daya Manusia yang berkualitas, berpengetahuan, menguasai teknologi dan informasi merupakan kunci sukses untuk upaya dalam membenahi kompleksitas masalah pendidikan.

\section{Efektivitas Kerja Guru}

Soetopo (2010: 51-57 ) mendefinisiskan keefektivan adalah ketepatan sasaran dari suatu proses yang berlangsung untuk mencapai tujuan yang telah ditetapkan sebelumnya. Pengertian keefektivan khususnya dalam organisasi menjadi masalah yang kontroversial sebagaimana dipaparkan bahwa untuk mengukur keefektifan organisasi dapat dilihat dari berbagai sudut tinjau. mulyasa (dalam wahyudi, 2009: 88-90) menjelaskan bahwa efektivitas berkaitan erat dengan perbandingan antara tingkat pencapaian tujuan dengan rencana yang telah disusun sebelumnya. Selanjutnya dikatakan bahwa efektivitas adalah suatu ukuran yang memberikan gambaran tentang pencapaian target. Menurut Komariah dan Triatna (2009:7) bahwa efektivitas menunjukan ketercapaian sasaran atau tujuan yang telah ditetapkan. Berdasarkan pengertian diatas, efektivitas menunjukan pada taraf pencapaian sasaran atau tujuan yang telah ditetapkan sebelumnya.

Pidarta (2010: 19) mengemukakan bahwa suatu pekerjaan dikatakan efektif kalau pekerjaan itu memeberi hasil yang sesuai dengan krteria yang ditetapkan semula, dengan kata lain kalau pekerjaan itu mampu merealisasikan tujuan organisasi dalam aspek yang dikerjakan itu. Warsita (2008: 287) menjelaskan bahwa efektivitas menekankan pada perbandingan antara rencana dengan tujuan yang dicapai.

Berdasarkan pada beberapa teori tentang efektivitas kerja guru dapat di sintesiskan bahwa taraf pencapaian hasil kerja guru dalam mengelola proses pembelajaran dengan tepat sasaran dan waktu, terarah dan sistematis, dan terciptanya aktivitas pembelajaran yang kondusif, serta tercapainya tujuan pembelajaran sesuai dengan yang telah direncanakan sebelumnya. 


\section{Kepemimpinan Visioner Kepala Sekolah}

Menurut Robbins dalam Syarifuddin, mengemukakan bahwa kepemimpinan adalah kemampuan mempengaruhi suatu kelompok ke arah pencapaian suatu tujuan "(Syarifudin, 2011: 108). Black (dalam Samsudin, 2006: 287) mengemukakan bahwa "kepemimpinan adalah kemampuan meyakinkan dan menggerakkan orang lain agar amu bekerja sama di bawah kepemimpinannya sebagai suatu tim untuk mencapai suatu tujuan tertentu." Pengertian serupa juga disampaikan Hasibuan (2007: 170) bahwa "kepemimpinan adalah cara seorang pemimpin mempengaruhi perilaku bawahan, agar mau bekerja sama dan bekerja produktif untuk mencapai tujuan organisasi." Menurut Terry (dalam Kartono, 2005:.49) menganggap kepemimpinan sebagai suatu kegiatan untuk mempengaruhi orang agar bekerja dengan rela untuk mencapai tujuan bersama. Pendapat serupa juga disampaikan oleh Hoyt (dalam Kartono, 2005: 49) bahwa "Kepemimpinan adalah seni untuk mempengaruhi tingkah laku manusia, kemampuan untuk membimbing orang".

Menurut Bafadal (2003: 32) mengatakan "Kepemimpinan sebagai keseluruhan proses mempengaruhi, mendorong, mengajak, menggerakkan dan menuntun orang lain dalam proses kerja agar berfikir, bersikap dan bertindak sesuai dengan aturan yang berlaku dalam rangka mencapai tujuan yang telah ditetapkan".

Berdasarkan teori di atas dapat disintesiskan bahwa kepemimpinan visioner kepala sekolah adalah perilaku pemimpin dalam mencetuskan ide atau gagasan suatu visi sekolah melalui diskusi dengan personil dalam merumuskan tujuan masa depan sekolah yang dicitacitakan dan dicapai melalui komitmen semua personil melalui proses sosialisasi, transformasi, implementasi gagasan-gagasan ideal.

\section{Hakikat Inovasi}

Inovasi berasal dari kata "innovation" yang bermakna hasil yang baru atau pembaharuan. Sa'ud (2008: 3) "mendefinisikan inovasi sebagai ide, barang, kajian,, metode yang dirasakan dan diamati sebagai suatu hal yang baru bagi sesorang, sekelompok orang atau masyarakat." Schermerhorn (2010: 376) mengungkapkan bahwa "innovation is the process of creating new ideas and putting them into practice." Inovasi adalah proses menciptakan ide baru dan menempatkannya dalam praktik. Dey (2012: 3) mengungkapkan bahwa " innovation is the process of translating what starts off as a creative idea or nation into something useful that people want and need is innovation. " inovasi adalah proses menerjemahkan apa yang dimulai sebagai ide kreatif atau gagasan menjadi sesuatu yang berguna yang orang inginkan dan butuhkan. Gaymor (2009: 6)menyatakan bahwa "innovation is about taking ideas and developing them into products and services and bringing them to the marketplace to generate new economic growth." Inovasi adalah tentang mengambil ide dan mengembangkannya menjadi produk dan jasa dan membawanya kepasar untuk menghasilkan pertumbuhan ekonomi baru.

Andriopoulos dan Dawson (2009: 28 ) mendefinisikan inovasi sebagai upaya menafsirkan ide-ide ke dalam bentuk, kegiatan dan pelayanan baru yang berguna dan bermanfaat. Inovasi merupakan kegiatan pengekplorasian gagasan-gagasan baru. Senada dengan teori di atas, Robbins (2013: 626) mengemukakan bahwa "inovasi adalah sebuah ide baru yang diaplikasikan untuk menciptakan atau mengembangkan (a) produk, (b) proses, (c) pelayanan. Robbin menyatakan bahwa inovasi merupakan perubahan, meskipun berasal dari pengembangan yang sedikit ataupun perubahan yang radikal."

Berdasarkan teori-teori di atas dapat disintesiskan bahwa inovasi adalah aktivitas weujudkan dan mengimplementasikan ide-ide baru dengan maksud untuk melakukan perubahan dan meningkatkan pencapaian tujuan. 


\section{METODE PENELITIAN}

Penelitian ini menggunakan metode survei dengan pendekatan korelasional, yaitu mencari nilai koefisien korelasi yang signifikan dari hubungan antarvariabel dan kontribusi yang dihasilkannya. Populasi dalam penelitian ini adalah seluruh guru MIS Kecamatan Cicurug Kabupaten Sukabumi yang berstatus guru honor dengan jumlah guru sebanyak 142 orang. Jumlah sampel dalam penelitian ini dibulatkan menjadi 105 orang guru.

Teknik pengambilan sampel menggunakan teknik Proportional random sampling, yaitu jumlah sampel berimbang dengan jumlah guru yang ada pada suatu sekolah. Teknik Proportional random sampling merupakan teknik pengambilan sampel secara acak di mana setiap individu dalam populasi mempunyai peluang yang sama untuk dijadikan sampel. Untuk menentukan jumlah sampel dari masing-masing sekolah dengan menggunakan rumus Slovin

\section{HASIL PENELITIAN}

\section{Pengujian Persyaratan Analisis}

\section{Uji Normalitas}

Persyaratan galat baku berdistribusi normal adalah jika $\mathrm{L}_{0}<\mathrm{L}_{\mathrm{t}}$. Dari hasil perhitungan uji normalitas galat baku taksiran $\left(\mathrm{Y}-\hat{\mathrm{Y}}_{1}\right)$ variabel Efektivitas Kerja Guru (Y) atas Kepemimpinan Visioner Kepala Sekolah $\left(\mathrm{X}_{1}\right)$, diperoleh nilai $\mathrm{L}_{0}$ maksimum sebesar 0,0603, dengan $\mathrm{L}_{\text {tabel }}$ sebesar 0,0865 . Karena $\mathrm{L}_{0}<\mathrm{L}_{\mathrm{t}}$ maka, galat baku taksiran $\left(\mathrm{Y}-\hat{\mathrm{Y}}_{1}\right)$ persamaan regresi variabel Efektivitas Kerja Guru (Y) atas Kepemimpinan Visioner Kepala Sekolah $\left(\mathrm{X}_{1}\right)$ dapat disimpulkan berasal dari populasi yang berdistribusi normal.

Perhitungan uji normalitas galat baku taksiran $\left(\mathrm{Y}-\hat{\mathrm{Y}}_{2}\right)$ variabel Efektivitas Kerja Guru (Y) atas Inovasi $\left(\mathrm{X}_{2}\right)$, menghasilkan nilai $\mathrm{L}_{0}$ maksimum sebesar 0,0649 , sedangkan $\mathrm{L}_{\text {tabel }}$ sebesar 0,0865 . Persyaratan galat baku berdistribusi normal adalah jika $\mathrm{L}_{0}<\mathrm{L}_{\mathrm{t}}$. sehingga, galat baku taksiran $\left(\mathrm{Y}-\hat{\mathrm{Y}}_{2}\right)$ persamaan regresi variabel Efektivitas Kerja Guru $(\mathrm{Y})$ atas Inovasi $\left(\mathrm{X}_{2}\right)$ dapat disimpulkan berasal dari populasi yang berdistribusi normal.

\section{Uji Homogenitas}

Berdasarkan hasil perhitungan, homogenitas data Efektivitas Kerja Guru (Y) atas Kepemimpinan Visioner Kepala Sekolah $\left(\mathrm{X}_{1}\right)$ diketahui harga $\chi^{2}$ hitung sebesar 21,448, sedangkan $\chi_{\text {tabel }}^{2}$ sebesar 66,3386 . Maka dapat disimpulkan bahwa, data variabel Efektivitas Kerja Guru (Y) atas variabel Kepemimpinan Visioner Kepala Sekolah $\left(\mathrm{X}_{1}\right)$ berasal dari populasi yang homogen.

Hasil perhitungan, homogenitas data Efektivitas Kerja Guru (Y) atas Inovasi $\left(\mathrm{X}_{2}\right)$

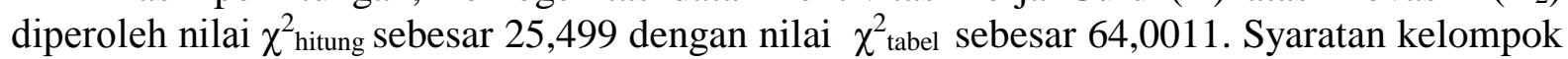

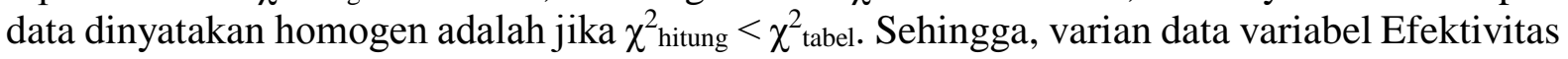
Kerja Guru $(\mathrm{Y})$ atas variabel Inovasi $\left(\mathrm{X}_{2}\right)$ dapat disimpulkan berasal dari populasi yang homogen

\section{Pengujian Hipotesis}

\section{Hubungan antara Kepemimpinan Visioner Kepala Sekolah $\left(\mathrm{X}_{1}\right)$ dengan Efektivitas Kerja Guru (Y)}

Berdasarkan hasil perhitungan koefisien korelasi, diperoleh nilai koefisien korelasi $\left(\mathrm{r}_{\mathrm{y} 1}\right)$ sebesar 0,5486 dan nilai koefisien determinasi $\left(\mathrm{r}^{2} \mathrm{yl}\right)$ sebesar 0,3009. Hal ini menunjukkan bahwa 30,09 \% variabel Efektivitas Kerja Guru dapat diterangkan oleh varibel Kepemimpinan Visioner Kepala Sekolah.

Uji signifikansi koefisien korelasi menunjukkan bahwa $t_{\text {hitung }}=6,6262$ sedangkan $t_{\text {tabel }}$ pada taraf signifikansi $0,05=1,9833$ dan taraf signifikansi $0,01=2,62441$. Hal ini menunjukkan bahwa $t_{\text {hitung }}>t_{\text {tabel. }}$. Syarat signifikan adalah jika $t_{\text {hitung }}>t_{\text {tabel. }}$. Sehingga korelasi 
antara variabel Kepemimpinan Visioner Kepala Sekolah $\left(\mathrm{X}_{1}\right)$ dengan variabel Efektivitas Kerja Guru (Y) adalah sangat signifikan $\left(\mathrm{t}_{\mathrm{h}}=6,6262>2,62441=\mathrm{t}_{\mathrm{t}(\alpha=0,01)}\right)$. Dengan demikian, hipotesis nol $\left(\mathrm{H}_{0}\right)$ ditolak dan hipotesis alternatif $\left(\mathrm{H}_{1}\right)$ diterima. Artinya, terdapat hubungan positif yang sangat signifikan antara Kepemimpinan Visioner Kepala Sekolah dengan Efektivitas Kerja Guru.

\section{Hubungan antara Inovasi $\left(\mathbf{X}_{2}\right)$ dengan Efektivitas Kerja Guru (Y)}

Hasil perhitungan koefisien korelasi, menunjukkan nilai koefisien korelasi $\left(r_{\mathrm{y} 2}\right)$ sebesar 0,8028 dan nilai koefisien determinasi $\left(\mathrm{r}_{\mathrm{y} 1}^{2}\right)$ sebesar 0,6446 Hal ini menunjukkan bahwa 64,46 $\%$ variabel Efektivitas Kerja Guru dapat diterangkan oleh varibel Inovasi.

Uji signifikansi koefisien korelasi menunjukkan bahwa $t_{\text {hitung }}=13,9943$ sedangkan $t_{\text {tabel }}$ pada taraf signifikansi $0,05=1,9833$ dan taraf signifikansi $0,01=2,62441$. Hal ini menunjukkan bahwa thitung $>t_{\text {tabel }}$. Dengan demikian Hubungan antara variabel Inovasi $\operatorname{Guru}\left(\mathrm{X}_{2}\right)$ dengan variabel Efektivitas Kerja Guru $(\mathrm{Y})$ adalah sangat signifikan $\left(\mathrm{t}_{\mathrm{h}}=13,9943\right.$ > $\left.2,62441=\mathrm{t}_{\mathrm{t}(\alpha=0,01)}\right)$. Dengan demikian, hipotesis nol $\left(\mathrm{H}_{0}\right)$ ditolak dan hipotesis alternatif $\left(\mathrm{H}_{1}\right)$ diterima. Artinya, terdapat hubungan positif yang sangat signifikan antara Inovasi dengan Efektivitas Kerja Guru.

\section{Hubungan antara Kepemimpinan Visioner Kepala Sekolah $\left(\mathbf{X}_{1}\right)$ dan Inovasi $\left(\mathbf{X}_{2}\right)$ secara bersama-sama dengan Efektivitas Kerja Guru (Y)}

Berdasarkan hasil perhitungan koefisien korelasi, kekuatan hubungan antara variabel Kepemimpinan Visioner Kepala Sekolah $\left(\mathrm{X}_{1}\right)$ dan variabel Inovasi Guru $\left(\mathrm{X}_{2}\right)$ secara bersamasama dengan variabel Efektivitas Kerja Guru (Y) adalah $\mathrm{R}_{\mathrm{y} 12}=0,8144$, dan nilai koefisien determinasi $\mathrm{R}_{y 12}^{2}$ sebesar 0,6633. Hal ini menunjukkan bahwa 66,33\% variabel Efektivitas Kerja Guru dapat diterangkan baik oleh variabel Kepemimpinan Visioner Kepala Sekolah dan varibel Inovasi.

\section{Uji korelasi parsial}

Berdasarkan hasil perhitungan, koefisien korelasi $\mathrm{X}_{1}$ dengan $\mathrm{Y}$ jika $\mathrm{X}_{2}$ dikontrol diperoleh nilai $r_{y \cdot 12}=0,2295$. Untuk menguji tingkat signifikansi koefisien korelasi parsial yang dikontrol oleh variabel $\mathrm{X}_{2}$ dilakukan dengan uji t. Berdasarkan hasil perhitungan, diperoleh nilai $t_{\text {hitung }}=2,3811$, sedangkan $t_{\text {tabel }}$ pada taraf signifikansi $0,05=1,983$ dan taraf signifikansi $0,01=2,623$. Hal ini menunjukkan bahwa $t_{\text {hitung }}>t_{\text {tabel}}$. Syarat signifikan adalah jika $t_{\text {hitung }}>$ $\mathrm{t}_{\text {tabel. }}$

Dengan demikian, korelasi antara variabel Inovasi $\left(\mathrm{X}_{2}\right)$ dengan Efektivitas Kerja Guru (Y) dimana nilai $\mathrm{X}_{1}$ (variabel Kepemimpinan Visioner Kepala Sekolah) dikontrol atau tetap adalah sangat signifikan, dengan kontribusi sebesar 0,5183 (51,83\%).

\section{PEMBAHASAN}

\section{Hubungan Antara Kepemimpinan Visioner Kepala Sekolah $\left(X_{1}\right)$ dengan Efektivitas Kerja Guru (Y)}

Pengujian hipotesis bahwa terdapat hubungan positif antara variabel $\mathrm{X}_{1}$ dengan variabel $\mathrm{Y}$ dilakukan dengan uji signifikansi koefisien korelasi yaitu dengan uji $\mathrm{t}$, dengan kriteria pengujian signifikansi koefisien korelasi adalah jika $t_{\text {hitung }}>t_{t a b e l}$, maka koefisien korelasi dinyatakan signifikan. Hasil perhitungan diperoleh $t_{\text {hitung }}=6,6262$ sedangkan $t_{\text {tabel }}=1,9833(\alpha$ $=0,05)$, dan $t_{\text {tabel }}=2,62441(\alpha=0,01)$ berarti koefisien korelasi antara Kepemimpinan Visioner Kepala Sekolah $\left(\mathrm{X}_{1}\right)$ dengan Efektivitas Kerja Guru $(\mathrm{Y})$ adalah sangat signifikan. Dengan demikian, hipotesis nol $\left(\mathrm{H}_{0}\right)$ ditolak dan hipotesis alternatif $\left(\mathrm{H}_{1}\right)$ diterima. Artinya, terdapat 
hubungan positif yang sangat signifikan antara Kepemimpinan Visioner Kepala Sekolah dengan Efektivitas Kerja Guru.

Hasil penelitian ini juga sejalan dengan hasil penelitian Robbins (dalam Wahyudi, 2009: 24) "Kepemimpinan Visioner Kepala sekolah adalah kemampuan pimpinan untuk menciptakan dan mengartikulasikan suatu visi yang realistik, dapat dipercaya, atraktif tentang masa depan bagi suatu organisasi atau unit organisasional yang terus bertumbuh dan meningkat sampai saat ini. Komariah (dalam Wahyudi, 2009: 24) mengemukakan "Kepemimpinan visioner (visionary leadership) dapat diartikan sebagai kemampuan pemimpin dalam mencipta, merumuskan, mengkomunkasikan, mensosialisasikan, mentransformasikan, dan mengimplementasikan pemikiran-pemikiran ideal yang berasal dari dirinya atau sebagai hasil interaksi sosial diantara anggota organisasi dan stakeholder yang diyakini sebagai cita-cita organisasi di masa depan yang harus dicapai melalui komitmen semua personil.

Berdasarkan hasil penelitian dan pembahasan diatas maka dapat diindikasikan bahwa salah satu upaya untuk meningkatkan Efektivitas Kerja Guru adalah dengan meningkatkan Kepemimpinan Visioner Kepala Sekolah. Hubungan positif yang signifikan antara Kepemimpinan Visioner Kepala Sekolah dengan Efektivitas Kerja Guru mengandung arti bahwa semakin baik pelaksanaan Kepemimpinan Visioner Kepala Sekolah, maka semakin baik pula pencapaian Efektivitas kerja guru.

\section{Hubungan Antara Inovasi $\left(X_{2}\right)$ dengan Efektivitas Kerja Guru (Y)}

Pengujian hipotesis bahwa terdapat hubungan positif antara variabel $\mathrm{X}_{2}$ dengan variabel Y dilakukan uji signifikansi koefisien korelasi melalui uji t. Kriteria pengujian signifikansi koefisien korelasi adalah jika $t_{\text {hitung }}>t_{\text {tabel, }}$ maka koefisien korelasi dinyatakan signifikan. Dari hasil perhitungan diperoleh $t_{\text {hitung }}=13,9943$ sedangkan $t_{\text {tabel }}=1,9833(\mathrm{n}=104$ dan $\alpha=0,05)$, dan $t_{\text {tabel }}=2,62441(\mathrm{n}=105$ dan $\alpha=0,01)$ berarti koefisien korelasi antara Inovasi $\left(\mathrm{X}_{2}\right)$ dengan Efektivitas Kerja Guru (Y) adalah sangat signifikan. Dengan demikian, hipotesis nol $\left(\mathrm{H}_{0}\right)$ ditolak dan hipotesis alternatif $\left(\mathrm{H}_{1}\right)$ diterima. Artinya, terdapat hubungan positif yang sangat signifikan antara Inovasi dengan Efektivitas Kerja Guru.

Sintesis teori di atas juga merujuk dan mempertimbangkan pandangan Steve M. Jex (2002: 109) mengungkapkan, inovasi adalah kondisi ketika pegawai menghasilkan ide-ide atau konsep-konsep baru yang akan meningkatkan tujuan organisasi. Bentuk inovasi yang paling terlihat dalam organisasi adalah produk, pelayanan, pemasaran, dan distribusi yang baru.

Hasil penelitian ini juga sejalan dengan hasil penelitian yang telah dilakukan oleh Andriopoulos dan Dawson (2009: 28 ) mendefinisikan inovasi sebagai upaya menafsirkan ideide ke dalam bentuk, kegiatan dan pelayanan baru yang berguna dan bermanfaat. Inovasi merupakan kegiatan pengekplorasian gagasan-gagasan baru. Hubungan positif yang signifikan antara Inovasi dengan Efektivitas Kerja Guru memberikan arti bahwa semakin baik Inovasi yang terjalin dalam pekerjaannya, maka semakin baik pula rasa Efektivitas kerja guru dalam menunaikan tugas-tugasnya.

Berdasarkan hasil penelitian dan pembahasan diatas maka dapat diindikasikan bahwa salah satu upaya untuk meningkatkan Efektivitas Kerja Guru adalah dengan meningkatkan Inovasi.

\section{Hubungan Antara Kepemimpinan Visioner Kepala Sekolah dan Inovasi Secara Bersama-sama dengan Efektivitas Kerja Guru.}

Menguji hipotesis bahwa terdapat hubungan positif antara variabel Kepemimpinan Visioner Kepala Sekolah $\left(\mathrm{X}_{1}\right)$ dan Inovasi $\left(\mathrm{X}_{2}\right)$ dengan Efektivitas Kerja Guru (Y) diperlukan uji signifikansi yaitu dengan uji F. Kriteria pengujian signifikan koefisien korelasi ganda adalah jika $F_{\text {hitung }}>F_{\text {tabel, }}$ maka koefisien korelasi ganda adalah sangat signifikan. Berdasarkan hasil perhitungan diperoleh $F_{\text {hitung }}=100,4552$ sedangkan $F_{\text {tabel }}=3,083(\mathrm{dk}$ pembilang $=2$, dk 
penyebut $=103$, dan $\alpha=0,05)$, dan $\mathrm{F}_{\text {tabel }}=4,813(\mathrm{dk}$ pembilang $=2$, dk penyebut $=103$, dan $\alpha$ $=0,01)$ berarti koefisien korelasi antara Kepemimpinan Visioner Kepala Sekolah $\left(\mathrm{X}_{1}\right)$ dan Inovasi $\left(\mathrm{X}_{2}\right)$ dengan Efektivitas Kerja Guru (Y) adalah sangat signifikan. Dengan demikian, hipotesis nol $\left(\mathrm{H}_{0}\right)$ ditolak dan hipotesis alternatif $\left(\mathrm{H}_{1}\right)$ diterima. Artinya terdapat hubungan positif yang sangat signifikan antara Kepemimpinan Visioner Kepala Sekolah dan Inovasi secara bersama-sama dengan Efektivitas Kerja Guru.

Hal ini sejalan dengan ungkapan Gilbert H. Hunt dan Keneth D. Moore (dalam Rosyada, 2007: 118-119) memaparkan bahwa "untuk menciptakan kelas efektif dalam peningkatan efektivitas proses pembelajaran tidak bisa dilakukan secara parsial, tetapi harus holistis. Dijelaskan pula bahwa Hunt dan Moore membahas topik dan kisaran persoalan yang sama bahwa guru efektif itu harus memulai dengan perencanaan pembelajaran, lalu mengkomunikasikan perencanaan tersebut dengan siswa, kemudian menyelenggarakan proses pembelajaran, mengelola kelas sehingga efektif, dan terakhir melakukan evaluasi terhadap proses dan hasil belajar, yang hasilnya akan menjadi input untuk perencanaan berikutnya.

Dengan demikian, Hunt dan Moore mengisyaratkan bahwa proses pembelajaran yang terarah dan sistematis serta memperhatikan tahapan-tahapan yang dilakukan dengan benar, maka efektivitas kerja guru dalam pembelajaran akan tercapaidan menghasilkan kompetensi siswa yang diharapkan. Tentunya dalam proses pecapaian tujuan pembelajaran itu guru tidak bersifat individual, tetapi harus melibatkan siswa secara penuh karena yang belajar itu siswa. Guru bukan hanya sekedar mentransfer ilmu melainkan memfasilitasi siswa untuk belajar sehingga siswa mengalami apa yang terjadi dalam pembelajaran.

\section{KESIMPULAN}

Hasil analisis membuktikan bahwa terdapat hubungan yang positif antara Kepemimpinan Visioner Kepala Sekolah dan Inovasi baik sendiri-sindiri maupun secara bersama-sama dengan Efektivitas Kerja Guru. Hal ini mencerminkan bahwa untuk meningkatkan Efektivitas kerja guru dapat dilakukan dengan cara meningkatkan Kepemimpinan Visioner Kepala Sekolah dan perbaikan Inovasi.

\section{DAFTAR PUSTAKA}

Aan Komariah dan Cepi Triatna. 2010. Visionery Leadership: Menuju Sekolah Efektif . Jakarta: Bumi Aksara.

Ade Irwana. 2015. Kepemimpinan Visioner kepala Sekolah, Kinerja Guru Efektivitas Sekolah, Jurnal Ddministrasi Pendidikan. Vol. XXII No.2 Oktober.

Ali Imron. 2015. Pembinaan Guru di Indonesia. Jakarta: Pustaka Jaya 1995.

Bambang warsita. 2008. Teknologi Pembelajaran, Landasan dan Aplikasinya. Jakarta: Rineka Cipta.

Consantine Andriopoulos and Patrick Dawson. 2009. Managing Change, Creativity and Inovation. London: SAGE Publication Ltd.

Darwis S. Gani, Djoehana setyamidjaja dan Sumadi. 2008. Kepemimpinan dan organisasi Kependidikan. Bogor: Pascasarjana,UNPAK.

Dede Rosyada. 2007. Paradigma Pendidikan Demokrastis, Sebuah Model Pelibatan Masyarakat dalam Penyelenggaraan Pendidikan. Jakarta: Kencana Prenadan.

Diya R. Dey. 2012. Innovation in organization. Australian: Psychological Society.

E.Mulyasa. 2005. Menjadi Guru Profesional Menciptakan Pembelajaran Kreatif dan Menyenangkan. Bandung: PT Remaja Rosda Karya.

E.Mulyasa. 2004. Menjadi kepala Sekolah Profesional. Bandung: Remaja Rosdakarya,2004.

Faustino Cardoso G. 2002. Manajemen Sumber Daya Manusia. Yogyakarta: Andi 2002. 
Gerard H. (Gus) Gaymor. 2009. Perspectives on Innovation. USA: IEEE-USA.

Hadyat Soetopo. 2010. Perilaku Organisasi, Teori dan Praktek di Bidang Pendidikan. Bandung: Rosda Karya.

Jerald Greenberg and Robert A. Baron. 2008. Behavior in Organizations Nint Edition. New Jersey: Pearson Educatio.

John R. Schermerhom, jr., et.al., 2010. Organizational Behavior 11 edition. United states of America; John Wiley \& Sons inc.

M. Sobry Sutikno, Belajar dan Pembelajaran, Upaya Kreatif dalam Mewujudkan Pembelajaran Yang Berhasil, (Bandung 2008)

Made Pidarta. Manajemen Pendidikan Indonesia, Jakarta: Rineka Cipta,2004

Malayu S.P Hasibun, Manajemen Sumber Daya Manusia (Jakarta: PT. Bumi Aksara, 2007)

Maulana Akbar 2016, Kepemimpinan kepala sekolah, motivasi kerja, budaya sekolah, efektivitas kerja guru, Jurnal Manajemen pendidikan indonesia Vol. 8 No. 1 April 2016

Moch. Idochi Anwar. Administrasi Pendidikan dan Manajemen Pendidikan (Bandung Alfabeth,2004)

Moh. Uzer Usman, Menjadi Guru Profesional,( Bandung: PT Remaja Rosda Karya 1997)

MS Abas Suryana, Wajah dan Dinamika Pendidikan Anak Bangsa, (Yogya karta: Adicita Karya Nusa 2011)

Mista Sunarya 2017, inovasi pembelajaran dan efektivitas pembelajaran, jurnal EDU-RILIGIA Vol. 1 No. 2 April-Juni 2017

Rilla Apriani2015, Kepala sekolah Efektivitas kerja guru, ISSN 0000-0000, Ejournal.an.fisipunmul.org, ejournal administrasi negara vol. 3 (2) 2015: 564-577

Sadili Samsudin, Manajemen Sumber Daya Manusia (Bandung: CV. Pustaka Setia,2006)

Stephen P Robbins and Timothy A Judge, Organizational Behavior, (New York: Pearson Education,2013)

Steve M. Jex, Organizational Psychology: a Scientist-practitioner approach. (New York: John Wiley \& Sons. 2002)

Suciati, Peran Guru dalam Kegiatan Pembelajaran, dalam Modul Belajar dan Pembelajaran, (Jakarta: Pusat Penerbit Universitas Terbuka 2002)

Sudarmayanti. Sumber Daya Manusia dan Produktivitas Kerja, (Bandung: Mandar Maju 2001)

Syaiful Sagala, Administrasi Pendidikan Kontemporer (Bandung: Alfabeta,2006),

Syarifudin. 2011. Manajemen Pendidikan. Jakarta: Diadit Media.

Udin Saefudin Sa'ud. 2008. Inovasi Pendidikan. Bandung; Alfabeta.

W.S. Winkel. 2005. Psikologi Pengajaran. Yogyakarta: Media Abadi.

Wahyudin dan Kartawinata. 2001. Modul Manajemen Berbasis Sekolah. Bandung: Dinas Pendidikan Jawa Barat.

Wayudi. 2009. Kepemimpinan Kepala Sekolah dalam Organisasi Pembelajaran: Learning Organization. Bandung: Alfa Beta,2009.

Wood, et.al. 2001. Organisational Behaviour A Perspective. Australia: John Wiley \& Sons. 